

\title{
Affective textualities, generalizations and focalizations: fan reactions to Twin Peaks's 2014 paratextual return
}

\author{
Ross Garner, Cardiff University
}

\begin{abstract}
:
This article analyses audience postings to two online locations where reports leading up to the release of the Twin Peaks: The Entire Mystery (TEM) Blu-ray set were posted between January and August 2014. Theorizing this release as a paratextual return which coincided with the show's 'dispersed' $25^{\text {th }}$ anniversary (Garner 2016), the article argues three points: firstly, greater recognition of fan discourse within studies of anniversary-orientated returns is required as, to date, these have been avoided, creating an unquestioned assumption that affective responses to these occasions are uniformly positive (Hills 2013, 2015a). Secondly, discussing fans' affective responses to paratextual returns permits re-engaging with Laurence Grossberg's (1992a, 1992b) arguments and extending these to consider the range of contextual factors that can structure how and where fans express affect. Thirdly, by analysing the responses of Twin Peaks fans, work on the perceptions of the fan object that fans express (Gray 2003) can be extended to recognise affective textualities which react to the text in multiple ways in accordance with the significance afforded to Twin Peaks within individual mattering maps.
\end{abstract}

\section{Keywords:}

anniversary

returns 
paratextuality

affect

fandom

nostalgia

Twin Peaks

To date, the academic literature discussing returning screen-based properties can be critiqued on two grounds. Firstly, it has primarily focused on what I would call textual returns -media properties that are industrially resurrected or rebooted to either continue or relaunch the fictional world (Proctor 2012; Tryon 2013) - at the expense of considering what I would name paratextual returns. Paratextual returns can include when a particular text is resurrected as a re-release on either an established (e.g. DVD) or emergent (e.g. Blu-ray) platform with a view to (re-)framing its cultural significance to its (typically niche-fan) audience.

Anniversaries of media-derived content provide one example of paratextual returns as these are 'a standardised part of media culture' (Hills 2015a: 2) and are marked by industrial strategies which encourage fans to 'repurchase story material that they effectively already own' (Hills 2015b: 207). Paratextual returns which are fan-targeted and anniversaryorientated constitute the ideal-type of the '[n]iche anniversary' (Hills 2013: 226) which is 'marketed and sold to fans outside [of the] TV text' (Hills 2013: 226) and can involve repacking the object to address a variety of factors including technological enhancements (e.g. improved picture and sound quality). This does not mean that anniversary-based paratextual returns completely overlook adding to either textual or extra-textual narratives. As Matt Hills (2013: 226) recognizes, '[f]an-targeted, niche anniversary products bec[o]me increasingly concerned with ...offering something new to fan-consumers' such as specially-shot making- 
of features, interviews or previously-unreleased deleted scenes. These fan-orientated extras rarely occur at the textual level, however, as they are instead designed to (re-)frame and (re)affirm fan readings of the text itself (Gray 2010). Secondly, the primary way that returning screen-based properties have been discussed is from an industrial perspective rooted in commercial associations. These discourses are evident in relation to both textual (Lizardi 2014; Howard 2015) and paratextual returns: regarding the latter, Simone Murray (2005: 417) argues that re-releases are looked upon as 'representing almost pure profit' for license holders, whilst Hills's (2013: 226) characterization of niche anniversaries deems these products of the 'commemoration industry'.

The consequences of these conflations and discourses are multiple. By failing to distinguish between textual and paratextual returns, an assumption arises that there is no difference between the two forms when they exhibit dissimilar relationships to technology, level of narrative engagement and intended audience (e.g. fan or 'mainstream'). Additionally, the enduring industrial reading of anniversary paratextual returns has contributed towards the analysis of fan reactions to rumours and speculation of these becoming an analytical absence. How do fans react to news concerning an anniversary re-release? What affective responses might be directed towards this news and/or the fan object? How might these affective reactions further our understandings of the forms of textuality that fans construct within contexts of renewed visibility and commemoration? Responding to these questions, this article analyses postings to two online sites to consider how respondents reacted to speculation concerning the return of Twin Peaks (ABC 1990-1991) between January and August 2014 in the run-up to the release of TEM.

Twin Peaks was a cultural phenomenon in the US during its initial transmission period, with academic commentary having frequently noted its introduction of visuallysophisticated, narratively complex 'quality' TV tropes to network television (Thompson 
1996; Mittell 2015). The series also gained niche-cult status in multiple non-domestic territories during the early 1990s (Halskov 2015) and has sustained a diverse-but-dedicated range of fan attachments in the period since its abrupt cancellation (Hayes and Boulègue 2013). During these ensuing years, Twin Peaks previously experienced anniversaryorientated paratextual returns such as the release of both series as a special edition DVD box set in the UK in 2010 (Hills 2015b: 197). However, the release of the TEM on to mark Twin Peaks's $25^{\text {th }}$ was significant for two reasons: firstly, it marked the first time that all 30 episodes of the TV series as well as prequel movie Twin Peaks: Fire Walk with Me (Lynch, 1992; $F W W M$ ) had been commercially-available together. Additionally, bonus content included 90 minutes of footage deleted from the theatrical cut of $F W W M$ which was re-edited into 'The Missing Pieces' and a specially-shot two-part sequence directed by David Lynch named 'Between Two Worlds' where he interviews members of the Palmer family both in and out of character. 'Between Two Worlds' featured a 'highly unusual blurring of diegetic and extradiegetic knowledge, seeming to place David Lynch oneirically inside "his" Twin Peaks's narrative universe' (Hills 2015b: 207) and, for some, the featurette's premise may destabilize the distinction between textual and paratextual returns that I have discussed., Instead, this may make TEM readable as a para/textual return because of its blurring of fiction and reality. Despite these complications, 'Between Two Worlds' remains tied to discourses of paratextuality as it was created solely as part of the Blu-ray set, rather than being promoted and sold as a diegetic continuation of Twin Peaks. Nevertheless, this ontological slipperiness alludes to the merging of other cultural categories around Twin Peaks's $25^{\text {th }}$ such as diegetic and extra-diegetic dates (e.g. 2014 being '25 years' since the series' narrative events rather than its initial transmission; Hills 2015b).

Secondly, Twin Peaks's silver jubilee was a further atypical anniversary because the commemoration constituted 'a "dispersed anniversary" (Garner 2016: 42; original emphasis) 
which originated 'within unofficial and nebulously-dispersed paratexts' (Garner 2016: 49) rather than through official publicity outlets (as has been the norm with previous studies of media-derived anniversaries; see below). Yet, despite Twin Peaks's $25^{\text {th }}$ having already generated high levels of scholarly attention, one noticeable absence has been the analysis of fan reactions to news concerning the Blu-ray release, an omission which provides the motivation for this article.

The discussion develops three arguments: firstly, when considering media-derived anniversaries, it is highlighted that greater attention should be paid towards fan reactions as the primary focus has either been to study institutionally brand-managed media anniversaries (Hills 2013, 2015a, 2015b) or including fan voices as an anticipated part of these strategies (Bell and Deller forthcoming). Discussing an atypical commemoration like Twin Peaks's $25^{\text {th }}$ develops how we understand media-derived anniversaries as the differences between what I have named praeventus and inseperatus in media res commemorations can be recognized. These terms relate to the level of industrial anticipation demonstrated and, as the empirical audience research demonstrates, generate affective responses from fans which are linked to the specificity of how the anniversary is positioned. Secondly, addressing fan reactions to anniversary paratextual returns requires re-engaging with the concept of affect within Fan Studies by expanding upon Laurence Grossberg's (1992a, 1992b) positions to recognize social constructionist theories (Gergen 1999). Grossberg's (1992a: 80) concept of the 'mattering map' is developed to incorporate the ways that affect becomes manifested through social, cultural and historical structures of signification within fan identities. Thirdly, analysing audience posts from a Grossbergian perspective results in discourses of what I have named affective generalization and temporal-affective focalization being identified. Whilst affective generalizations may seem straightforward, these statements build upon Jonathan Gray's (2003) arguments concerning the forms of textuality constructed by different audience 
groups by noting differences between interpretive and what I have named affective textualities. Additionally, discourses of temporal-affective focalization are less uniform than their generalized counterparts, but allude to the role that nostalgia plays in maintaining individual mattering maps. The significance of these arguments is that differentiating between the different levels of (cult) textual return, and addressing audience negotiations of news related to a paratextual return, brings the hitherto overlooked concept of fan affect into the study of media anniversaries and allows this concept to be re-considered within Fan Studies to better understand the myriad forms of affect observable within anniversary contexts.

\section{Methodology}

The data was collected from articles published to two websites. The first was MailOnline, the website for right-wing British newspaper The Daily Mail, and were made in relation to a report discussing a leaked casting call which explicitly mentioned David Lynch and Twin Peaks in early January 2014 (Maxwell 2014). Comments posted to MailOnline were selected for two reasons: firstly, MailOnline allows audiences to openly comment on each of its published articles. Secondly, the website represents the most-visited news provider for global internet users (Turvill 2016), meaning that the comments posted demonstrate scope in terms of the sampled article's visibility. However, one constraint which must be reflexivelyacknowledged when using MailOnline is that 'comment-posting does not necessarily signify fannish dedication, although it can act as a sign of it ...online profiles ...have to be taken on trust.' (Duffett 2013: 257) Whilst some readers may question whether all of the comments used in this study are representative of 'fannish affect', the similarity between dominant 
discursive expressions on MailOnline and my second data source indicate corroboration between the two. This second site was the fan-run Welcome to Twin Peaks (WtTP). WtTP was chosen because it is the most prominent Twin Peaks fan-site, receiving over 700000 global visitors during this study's time period (January-July 2014; Quantcast n.d.) - a figure which implies its centrality to Twin Peaks fans' 'textual environments' (Couldry 2000: 67). Comments from three news posts detailing developments regarding the 'Between Two Worlds' shoot, and then confirmation of TEM, were used (Twin Pie 2014a, b and c) and, in total, a sample of 157 posts from both websites were collected. The data was analysed using semiotic discourse analysis and a grounded approach was taken by deploying a 'constantcomparative method' (Lindlof and Taylor 2011: 250) where thematically-similar postings were grouped (and re-grouped) by myself. Regarding ethical concerns, WtTP's comments sections is a public area where posters are aware that their posts will be viewable to all and no terms and conditions must be agreed to prior to posting. In contrast, MailOnline encourages adhering to their 'House Rules' when posting (Daily Mail n.d.) but these are loosely-enforced with regard to both submitting posts and the content which respondents supply. MailOnline is therefore also represents a public platform as readers are aware of the visibility of their comments. In line with Annette Markham and Elizabeth Buchanan's (2012) guidelines concerning privacy and harm, no ethical issues arose.

\section{Beyond monolithic assumptions: fans' affective responses to media-derived}

\section{anniversaries}

Media anniversaries are an emerging area of cultural analysis. With regard to television, this work has reflected on how the medium commemorates temporal landmarks regarding both historical events of national significance (Gray and Bell 2013: 100-129) and individual 
channels/services (Holdsworth 2011: 117-121). However, it is Hills's (2013, 2015a, 2015b)

work that has set the terms of debate concerning anniversaries of media content. Hills (2015a:

4) defines anniversaries (whether mediated, media-derived or otherwise) broadly as

'articulat[ing] affective intensities with an objective interval of time'. On the one hand, this

definition usefully recognizes that affective outpourings organized around either

quinquennial or decennial markers are recurrent characteristics of these occasions. On the other, Hills's approach is problematic because it treats affect as monolithic and this understanding produces an unquestioned assumption that all forms of emotional engagement with a media-derived anniversary will be celebratory. One reason for this is that the anniversary that Hills has primarily studied - Doctor Who's $50^{\text {th }}$ as disseminated through paratexts - demonstrated 'a commercial, brand logic' (2013: 230) as its meanings, and forms of encouraged affect, were centrally-managed by the BBC. Lorna Jowett, Kevin Lee Robinson and David Simmons (2016: 5) allude to this sustained positivity by stating:

The term 'celebrating' is used in its loosest sense ...Doctor Who was more than celebrated. It was canonized, lionized and idolized as one of the biggest achievements of not only telefantasy but also the television industry in general.

Limiting academic discussion of anniversaries and affect to institutionally-controlled examples results in fans' affective responses becoming marginalized. Empirical work exploring fan attitudes towards Doctor Who's $50^{\text {th }}$ anniversary is a noticeable absence across all of Hills's studies of this event as he instead prioritizes either theorizing how an anniversary fulfils industrial branding requirements $(2013 ; 2015 \mathrm{a})$ or analysing anniversary episodes (Hills 2014). On the infrequent occasions when fans are quoted, Hills limits these to “"Big Name Fans” ...[who] occupy... positions of symbolic and subcultural power' (Hills 
2010a: 237) in Doctor Who (or Twin Peaks - Hills 2015b) fandom. Restricting fan voice to 'Big Name Fans' positions these as representative of the fandom en masse whereas, in reality, fan communities are typically characterised by multiple reading formations (Halskov 2015: 164-89). This alludes to an absence within Hills's studies as the diversity of fans' affective responses to media-based anniversaries, as well as how these relate to notions of para/textual return, have been overlooked.

A recent study of a tele-anniversary by Stuart Bell and Ruth A. Deller (forthcoming) has included fan voices, but the comments they discuss arose in relation to a specific generic, platform, and anniversary context concerning tweets sent during the week-long $30^{\text {th }}$ anniversary celebrations for the soap opera EastEnders (BBC 1985- ). The tweets were generated in direct response to strategies implemented by the $\mathrm{BBC}$ and were designed to heighten the immediacy of this commemoration. Strategies included producing inserts, as well as an hour-long episode, which were transmitted live and releasing short-form videos insync with the narrative revelations which showcased the cast's reactions to the culmination of a long-running storyline. EastEnders's $30^{\text {th }}$ therefore created a new 'milestone moment' (Holdsworth 2011: 36) in the show's history, but it is arguable that fan comments were, to some extent, also anticipated with a view to 'driving social media traffic and ... wider media speculation, bringing attention to the show.' (Bell and Deller forthcoming). Thus, whilst fan tweets demonstrated multiple affective responses to the live elements including 'celebration, disappointment, humour, and confusion' (Bell and Deller forthcoming), these reactions formed part of the anniversary's official planning. What's more, the emphasis placed on copresence in terms of how audience engagement was encouraged can be read institutionally as fulfilling the BBC's public service responsibilities regarding 'the idea of liveness as a nationbuilding exercise' (Bell and Deller forthcoming) and 'rais[ing] the profile of the text' (Bell and Deller forthcoming) through social media to demonstrate the Corporation's public value. 
Additionally, when approached from a narrative perspective, this $30^{\text {th }}$ anniversary represents what I would call an in media res celebration occurring at the textual level as the "milestone moment' involved resolving a long-term serialised arc at the same time as initiating new storylines arising from this resolution (Bell and Deller forthcoming). Thus, although Bell and Deller usefully document a range of affective reactions that represent fans' paratextual play (Deller 2014), these engagements remain linked to ideas of institutional intentionality and a centrally-managed brand campaign.

Fan reactions to Twin Peaks's silver jubilee differ to Bell and Deller's example in three ways: firstly, rather than being generated in response to a heavily-publicized 'milestone moment', Twin Peaks's anniversary was initiated and sustained within the 'the non-corporate controlled axis' (Hardy 2011: 8) of media publicity. Instead of responding to a centralized brand campaign, the comments discussed below were initially reacting to unconfirmed adhoc speculation. This should not imply the construction of a false binary between 'authentic/organic fan reactions' and 'inauthentic/pre-planned brand management', however. Instead the distinction is made to reinforce the atypicality of Twin Peaks's $25^{\text {th }}$ celebrations and how different industrial approaches generate alternative contexts for expressing fan affect. Secondly, although Twin Peaks's 2014 anniversary was linked to a serialised narrative and demonstrates overlaps with an in media res anniversary, conceptual differences remain. Both Doctor Who and EastEnders's commemorations constitute praeventus in media res anniversaries as each was institutionally-anticipated and structured into their ongoing narrative design. In contrast, the lack of engagement with the ' 25 years' meta-paratext' (Garner 2016: 43) in the marketing of TEM suggests that it can be viewed as an inseperatus in media res anniversary. Although the anniversary's genesis arose from diegetically-focused readings concerning an unresolved enigma involving Agent Cooper (Kyle MacLachlan) and Laura Palmer (Sheryl Lee) from the show's (unplanned) finale ('Beyond Life and Death'), 
the lack of official recognition of this temporal significance in the Blu-ray set's official publicity implies that the fans' readings were unanticipated. Moreover, the narrative extension provided via 'Between Two Worlds' blurred distinctions between diegetic and extra-diegetic reality and focused more on paratextually re-framing existing narratives (at both levels) rather than providing new information for fans. Thirdly, the affective reactions discussed below arose from online web pages rather than a social media platform like Twitter. As previous research has demonstrated, different platforms generate specific forms of discourse such as Twitter's limitation to 140 characters (Williams 2013). Postings to online articles differ by permitting longer commentary as well as suggesting that respondents are participating in a conversation initiated by the (fan-)journalist writing the article (Thurman 2008), rather than engaging with the imagined audiences associated with Twitter hashtags (Anstead and O'Loughlin 2011: 453-454). Having differentiated Twin Peaks's 25 th and the audience comments sampled by this study, the ensuing discussion analyses the diversity of affective responses to Twin Peaks's paratextual return during its silver jubilee. However, one term that this article is yet to be defined is affect and it is necessary to do this to ensure that a rigorous conceptual framework is provided.

\section{Theorizing affect: Grossberg, signification and affective mapping}

William Proctor (2013: 207) has argued that 'Academic work on affect and emotion crosses numerous disciplines whilst marshalling a wide range of approaches'. Proctor's position reaffirms Lawrence Grossberg's (1992a: 80) comments on the topic, as he defines affect as 'perhaps the most difficult plane of human life to define and describe'. Affect's conceptual slipperiness partly arises 'because it is a-signifying (and contemporary theory is so heavily directed toward signifying practices), but also because there is no critical vocabulary to 
describe its different forms and structures.' (Grossberg 1992a: 80) Despite these challenges, trajectories for engaging with the concept within Cultural Studies have been pursued. Gilles Deleuze (1986) approached affect in relation to popular culture forms by considering how individual agents react to specific audio-visual stimuli such as the cinematic moving image. From this perspective, it has been argued that:

Organic images - such as humans - have complex nervous systems: accordingly, external perceptions generate internal intensities which traverse the body in a multitude of ways, giving rise to any number of different possible actions. (Deamer 2015: 37)

On the surface, Deleuze's position concerning affect overlaps with Grossberg's. Echoing Deleuze's stance that affect is a distinct state which differs from both emotions and desire because it is experienced bodily (and hence is pre-cognitive), Grossberg (1992b: 56-7) argues:

Affect is closely tied to what we often describe as the feeling of life. You can understand another person's life: you can share the same feelings and pleasures, but you cannot know how it feels. But feeling, as it functions here, is not a subjective experience. It is a socially constructed domain of cultural effects. Some things feel different from others, some matter more, or in different ways, than others. The same experience will change drastically as our mood or feeling changes. The same object, with the same meaning, giving the same pleasure, is very different as our affective relationship to it changes. Or perhaps it is more accurate to say that different affective 
relations inflect meanings and pleasures in very different ways. Affect is what gives 'color,' 'tone' or 'texture' to our experiences.

These attempts to separate affect out as a distinct part of our emotional spectrum have rightly been critiqued: as Proctor (2013: 207) summarises, 'This binary distinction is arguably rather unhelpful and tends to lead towards the oft-cited distinction between nature and culture in place of a dialectical relationship between affect/emotion operating hand in hand as two sides of the same coin.' Grossberg's theory of affect therefore needs advancing to recognise that 'emotion [acts] as a cultural construction ...not as a feature of our biological make-up' (Gergen 1999: 109). In other words, whilst affect might constitute conditions experienced at the bodily level, for these states to be recognised, classified and communicated by subjects they have to be filtered through the signifying practices of a shared linguistic culture. These social, cultural and historical dimensions are alluded to in Grossberg's theorizing, however, and addressing his comments on these issues distinguishes his approach from that of Deleuze. Firstly, Deleuzian perspectives arguably over-emphasise the interaction between individual subjects and technological apparatus. In contrast, Grossberg's (1992a, 1992b) approach adopts a broader scope by recognizing that myriad forms of popular culture (e.g. music, social interactions) can generate diverse forms of affect. This understanding is useful because it alludes to how various media forms, such as paratexts like news reports or Blu-ray releases, can produce affective responses. For Grossberg (1992a: 78), it is essential to take the role that myriad popular culture forms play in individual lived experience seriously as the fact that some groups (e.g. fans) care deeply about information concerning a particular programme or star indicates 'how "mattering” may have its own impact on history and daily life.' Expanding upon this assumption, he continues: 
For many people, certain forms of popular culture become taken-for-granted, even necessary, investments. As a result, specific cultural formations become "affective alliances." Their logic or coherence - which is often so difficult to define - depends upon their affective relationships, their articulated places within people's mattering maps. (Grossberg 1992a: 80)

The mattering map provides a second way of differentiating between Grossberg's theory of affect and that developed by Deleuze as the former begins to address that affective experiences are also shaped by contextual factors. Mattering maps are not solely rooted in subjective interrelationships between bodily reactions and technology. Instead, they are 'different forms, quantities and places of energy ... [which] "tell" people how to use and how to generate energy, how to navigate their way into and through various moods and passions, and how to live within emotional and ideological histories.' (Grossberg 1992a: 82) In other words, mattering maps are the historically-, socially- and culturally-specific ways that individuals manage 'the unrepresentable excess' (Grossberg 1992a: 83) that constitutes affect by directing these surpluses towards particular (in the current global capitalist milieu, commercial and popular) cultural artefacts via demonstrating fannish behaviours. Thus, rather than being purely individualised, Grossberg (1992b: 53-4) posits that affective investments, and the objects that make up an individual's mattering map, are part of the ongoing interplay between structure and agency. That is, an individual's affective investments 'are located in a set of cultural sensibilities' that precede the individual (fan) and, as a result of being sociocultural, assist in producing attachments to specific 'texts' (Grossberg 1992a: 71).

By linking affect to external and historically-determined contexts, Grossberg arguably invokes Pierre Bourdieu's (1984) concept of the habitus where social agents acquire 'a set of dispositions which generate... practices and perceptions' (Johnson 1993: 5) that endure and 
are transposable to different contexts and (media) forms over the course of that person's lifetime. The affective intensities which characterise fandom are therefore indicative of an individual's socially-derived tastes for, and ways of engaging with, popular cultural forms (Fiske 1992). This developed understanding of affect is useful because, as identified above, media anniversaries heavily play on generating fan affect. Recognizing that fans comments to online reports are manifestations of affective intensities, but that these are nevertheless the intersection of complex contextual factors necessitates that a range of concerns are considered throughout the ensuing analysis. These include individual fan biographies, sociodemographic factors, the opportunities and constraints for commenting that specific online media platforms provide, and the role of media conglomerates in encouraging such states through anniversary re-releases (Grossberg 1992b: 54). Shifting between these concerns whilst analysing audience postings provides a multi-layered understanding of how fans affectively negotiated Twin Peaks's 2014 paratextual return which does not seek to 'privilege either the text or the audience by giving one the power to determine the relationship' (Grossberg 1992b: 53).

Additionally, Grossberg's arguments permit theorizing the 'returning' aspect of Twin Peaks in 2014. He posits that 'At different points and places in our lives, we reorder the hierarchical relations among these differences. We redefine our own identity out of the relations among our differences; we reorder their importance, we invest ourselves more in some than in others.' (Grossberg 1992b: 58). Recognizing that a fan's mattering map is fluid implies the 'affective fluctuations' (Garner forthcoming) that are a normative part of individual fan experiences as objects can move in and out of significance over an extended time period. Analysing fan reactions to Twin Peaks's paratextual return in an anniversary context therefore raises questions concerning whether paratextual speculation generates a similar affective charge towards the show and in what ways the series forms part of an 
individual or shared mattering map. What's more, given that previous arguments concerning fan readings have demonstrated that 'Textuality shifts according to viewer engagement level' (Gray 2003: 65), the temporal dimension that underpins this study's sample allows for examining which aspects of Twin Peaks become positioned as of ongoing importance to individual mattering maps. Through examining audience comments, consideration of the different forms and roles of affect in relation to rumoured returns and anniversary celebrations can be discussed.

The following section explores these questions by initiating what Proctor (2013: 207) names 'an 'affective mapping' of fan reactions' to Twin Peaks's 2014 paratextual return. However, rather than reproducing Proctor's approach, what follows extends the idea of an affective map by rooting this in a theoretical grounding via Grossberg's arguments. This involves recognising that audience postings are articulated within broader discursive structures that are simultaneously social, cultural and historical. This theoretical grounding is something that Proctor overlooks in his affective mapping of fan reactions to the 2012 Disney-Lucasfilm merger as he instead approaches his online questionnaire responses as 'free' from the impact of contextual factors. As the next section argues, rooting analysis of audiences' affective reactions to an anniversary-based paratextual return to a Grossbergian perspective allows for the interplay between how fans align themselves with, or reject, broader socio-cultural ideologies to be addressed.

\section{Generalizations and focalizations: Twin Peaks, affective textualities and nostalgia}

The most frequent trend for comments left on both MailOnline and WtTP was for responders to post statements of what I have called generalized affect when negotiating news linked to Twin Peaks's paratextual return. Expressions of generalized affect constituted 22 of the 157 
posts analysed and were succinct statements which were left in either support or opposition towards reports of new Peaks-related footage appearing in 2014. These expressions discussed Twin Peaks at a general level by commenting on the show as a whole and directed their affect-laden sentiments towards this. Examples of positively-inflected statements included 'I loved Twin Peaks!!!' (Endless Nameless in Maxwell 2014: online), 'Alright! More of twin peaks is good with me!' (Adrien in Twin Pie 2014a: online) and 'I hope this is true' (jojo77 in Maxwell 2014: online). In contrast, negatively-toned equivalents included 'Hope not. Leave it alone!' (parkerlewis in Twin Pie 2014b: online) and 'No, that would turn out awfully. The original is perfect the way it is.' (Tim Tringle Jr. in Twin Pie 2014c). This final statement does allude to how some audience members introduced nuance into their affective expressions by acknowledging the temporal distance between the show's original airing and the present, subsequently positioning the original series as something 'past' which should be 'preserved' (see below). On the whole, though, these uncomplicated affective expressions support Grossberg's (1992a: 83-4) argument that 'Popular culture, operating with an affective sensibility, is a crucial ground where people give others, ...the authority to shape their identity and locate them within various circuits of power.' In these instances, Twin Peaks's continuing affective pull over each poster demonstrates how commercial popular forms provide fans with ways to 'organize their emotional and narrative life and identity' (Grossberg's 1992a: 83-4) by providing outlets through which audiences experience and communicate affective excesses ranging from excitement to disappointment.

On the surface, expressions of generalized affect may not warrant further analysis due to their brevity. In fact, if read in relation to previous studies of how different audience profiles discuss textuality, these statements might not appear particularly 'fannish' because of the level of generality demonstrated. Gray (2003: 74), for example, defines 'non-fan' identities as 'those viewers or readers who do view or read a text, but not with any intense 
involvement' and so 'experience a text at its outskirts.' (Gray 2003: 74) In other words, nonfans produce a different understanding of the text under discussion as their readings are not characterized by the detailed levels of narrative and production knowledge that typify how fans engage with a favoured text. Making this distinction between 'fan' and 'non-fan' perceptions of textual identity supports Gray's (2003: 75) aims to demonstrate how 'the very nature and physicality of the text changes when watched by the non-fan, becoming an entirely different entity' and that different audience groups produce alternative understandings of textuality which should be researched further.

Despite developing new vectors for audience research by recognizing that constructions of (fan) objects may change across interpretive communities whilst also generating both positive and negative affective responses, I would argue that a limitation of Gray's (2003) argument is that it focuses solely on audience interpretations and so overlooks how forms of textuality may become constructed differently on affective terms. Building upon Gray's arguments by adopting a Grossbergian perspective allows for differentiating between constructions of what I would call interpretive and affective textuality by audience respondents. For Grossberg (1992b: 61), the significant factor that distinguishes fan identities from those of other audience groups is the experience of affective excess. As he argues about rock music fans: 'the fact that it matters makes it different; it gives rock an excess which can never be experienced or understood by those outside of the rock culture.' Short statements such as 'Yiiippppeeeee!' (Me in Maxwell 2014: online) or 'Whoop!' (TingTong in Maxwell 2014: online) are readable as examples of Twin Peaks fans communicating such emotional intensity. What's more, the affective charges that characterize fan identities are, as Hills (2002: 65-6) argues, difficult for fans to signify in meaningful discourse such as providing self-rationalizing statements which capture the intensity of, in this instance, reacting to news of newly-shot Twin Peaks footage. Additionally, Rebecca Williams (2015: 129) has 
identified that fans frequently articulate 'expression[s] of hope' towards the possibility of a favoured text being resurrected, drawing attention to the enduring affective dimension that a fan text can have despite its cessation. Bringing these points together, it is arguable that speculation (or, latterly, confirmation) concerning a paratextual resurrection may stimulate an affective charge for individual fans that constitutes 'hope fulfilled' and the intensity of which is difficult to express linguistically. Addressing these differences between interpretation and affect positing that different understandings of a text such as Twin Peaks might be produced by fans depending upon the discursive mode through which news reports are reacted to. Rather than dismissing statements of affective generalization as indicative of a non-fan identity due to their lack of textual knowledge, such reactions might instead be viewed as constructions of affective textuality which articulate an eagerness to express intense fan feelings. Recognizing these differences points towards how different constructions of a favoured text may become articulated when discussing that object in a historical context where affect takes precedent.

Beyond expressing affective generalizations, a range of statements were observed which articulated ambivalence but discouraged easy thematic classification. For example, mixed responses included "I love Twin Peaks, but... I don't know about this. Not sure whether it's amazing or horrible news. I really, really hope it's going to be good, and not "forced" like many sequels can be..' (Siisio in Maxwell 2014: online) and 'Long-awaited episode \#30 of Twin Peaks finally happens after the world' $\mathrm{s}$ longest off-season, and it' $\mathrm{s} \cdots$ three minutes long!' (Jed in Twin Pie 2014a: online). This diversity is consistent with Proctor's (2013: 211) findings as his study also reflexively acknowledged that it became 'difficult to fit the varied responses into objective clusters' for the purposes of data organization. The fact that the comments sampled for this study encountered similar challenges during a historical-institutional moment of change indicates, on the one hand, the 
need for further scholarly research into similar situations across a range of franchises and media(ted) forms. On the other (and returning specifically to Twin Peaks's paratextual return), although there was not a uniform way in which the concept was engaged with, a noticeable trend across the postings was a range of engagements with nostalgia.

Nostalgia has been theorized as 'a periodising emotion' (Tannock 1995: 456) which creates meaning by juxtaposing discursively-bounded constructions of 'past' and 'present' and expresses yearning for the perceived absences assigned to the former time period. One way that nostalgic sentiments were expressed by the sampled respondents was by explicitly referencing the "“25 years meta-paratext" (Garner 2016: 43) that positioned 2014 as Twin Peaks's silver jubilee and a locus for fan affect:

a great idea with dale and laura 25 yrs later. (Dale III in Twin Pie 2014c: online)

I like how he is sticking to the 25 year thing, doing it in "real time". I used to love Twin Peaks, I was one of the obsessed people, but now all this time has passed and I'm not sure how I would feel about it. Maybe my tastes have changed, don't know... (bananagirl in Maxwell 2014: online)

The original started out so fascinatingly weird, but lost more and more of that quality as it ran. Wish they would use lots of the old actors and really make it about a $25 \mathrm{yr}$ gap with all the weirdness intact. Please don't make it ordinary! (Mandy110 in Maxwell 2014: online)

Svetlana Boym (2001: xvi) has argued that nostalgia must be considered 'a historical emotion' as it has developed multiple meanings across different disciplinary contexts since 
initially being used in the $17^{\text {th }}$ Century to refer to homesickness. At present, nostalgia is most commonly understood in socio-cultural terms as 'dependent on the modern conception of unrepeatable and irreversible time' (Boym 2001: 13) and the inability to directly revisit a particular time and space. This historical definition intersects with Grossberg's (1992a: 81) arguments as he posits that 'There are different forms of affective investments. These are the result of the energy of affect articulated through different principles of structuration.' Combining these perspectives suggests that nostalgia's contemporary meanings are part of wider socio-cultural structures that attach individuated meanings to internalized affective states and allow these to be classified by subjects at specific historical moments. Furthering this point, communicating experiences of nostalgia requires deploying what Annette Kuhn (2002: 10) names a 'past/present register'. This constitutes a discursive device which 'is about the way in which time is organised in memory discourse' (Kuhn 2002: 10) and 'marks accounts in which informants, usually unaware of doing so, shift or 'shuttle' back and forth between past and present standpoints.' (Kuhn 2002: 10) In the case of nostalgia, the 'past' is a construction that is brought into the 'present' to generate meaning and identity for the affective subject.

Approached from this perspective, the ' 25 years' meta-paratext provides a kernel for expressing various inflections of nostalgia. This occurred in an uncomplicated manner by attaching nostalgia to the value attached to certain forms of serialized narrative in television drama at present (Mittell 2015: 233-260) and using this discursive fusion to offer support for Twin Peaks's paratextual return at a (sub)culturally-constructed moment of temporal significance. Alternatively, the '25 years' meta-paratext was also used to reflexively compare Twin Peaks's affective impact 'then' and 'now'. The following post demonstrates further evidence of this: 'Despite a very disappointing ending, Twin Peaks is still one of the best shows ever made, and I think 25 years is way too long to try to pick up where it left off.' 
(Wild Mushroom in Maxwell 2014: online) By using the temporal marker to separate out and organize individualized feelings towards Twin Peaks at two different moments, such posts articulate a form of nostalgia that Fred Davis (1979: 21) names 'reflexive'. Reflexive nostalgia is when 'a Truth Squad or remonstrating Greek Chorus' (Davis 1979: 21) is introduced by the speaker to query their present-located affective responses. However, the reflexivity demonstrated by posters produced further variations: the second statement juxtaposes Twin Peaks's relevance 'then' and 'now', and so demonstrates how affective attachments to popular culture artefacts may change over time whilst still demonstrating the potential for being nostalgically remembered as part of a 'past' mattering map and, by extension, self. In contrast, the third poster (recalling the more nuanced statement of generalized affect mentioned above) identifies a 'projected ...essence of the series' (Hills 2010b: 5) concerning its perceived 'weirdness' which becomes positioned as the 'ideal' element that should be reproduced in the 'present'.

This latter expression of nostalgic affect intersects with what Boym (2001: 41) names 'restorative nostalgia', a form to which caution is expressed on ideological grounds as it 'proposes to rebuild the lost home' (Boym 2001: 41) and so has been evaluated as regressive. By identifying a perceived 'essence' of Twin Peaks and arguing for this 'quality' to be restored to the series during its paratextual return, the respondent's reading becomes positioned as the locus for nostalgic fan affect which must be restored. However, whilst restorative nostalgia should remain critiqued on ideological grounds when pertaining to the socio-political contexts, a Grossbergian perspective towards individual expressions of this form arguably says much about the role of mattering maps in expressions of fan identity. This is because the respondent accredits this reading of 'past' Twin Peaks sustained significance to their sense of self and their mattering map. This point is observable in other postings as respondents commented 'I watched this with my family and I was 8 . We knew it was wrong 
and disturbed but we loved it' (figaro0314 in Maxwell 2014: online) or 'It was fab from start to finish. ... would watch it again but Bob scares the bejesus out of me.' (Elvis was Here in Maxwell 2014: online) On the one hand, the reading of Twin Peaks that these posts provides is reflective of both a popular 'repisodic memory that reflect[s] the generic qualities of the series' (Spigel and Jenkins 1991: 135-136) rather than specific details, alongside a fanorientated 'discursive mantra' (Hills 2002: 67) concerning favourite elements from Twin Peaks, indicating how expressions of nostalgia always intersect with wider socio-cultural structures. On the other, identifying these individual 'qualities' suggests that Twin Peaks provides continuity between 'past' and 'present' understandings of a personal mattering map and provides a stability to the self. Rather than dismissing such expressions of nostalgia as ideologically-regressive, approaching them from a Grossbergian perspective allows for consideration of how expressions of nostalgia negotiate between external structures (guiding expressions of affect and their eventual locus) and individual agency through recourse to a remembered mattering map.

What's more, the different inflections of nostalgia articulated through audience negotiations of the '25 years' meta-paratext produce alternative constructions of affective textuality by generating individualized expressions of what I would call affective focalization. Expressions of affective focalization differ to the generalizations discussed above by identifying specific aspects of Twin Peaks as significant to the respondent's mattering map. However, as the above posts demonstrate, engagement with Twin Peaks's '25 years' metaparatext in 2014 can produce focalizations that are either directed extra-textually towards the fan-self and the previous affective charge that it had or textually towards (popular) memories of specific textual elements. More precisely, these statements represent what I would call affective-temporal focalizations as it is the aspect of time, and the use of the 'past/present' register to differentiate between 'then' and 'now', that moves the expressions of affect 
towards focusing upon specific aspects of the show's position with an individual's mattering map. Differentiating between affective-temporal focalizations and the affective generalizations mentioned above should not imply a hierarchy or value judgement between the two concepts, however. As previously discussed, affective generalizations can be read as short expressions of excessive affect that highlight the immediacy and intensity of fans reactions to news of a paratextual return. Instead, it should be noted that fans' negotiations of paratextual returns produce multiple inflections of affective discourse where the returning text's significance to an individual mattering map can be discussed at different levels relating to their fan/self-identity.

\section{Conclusion}

Instead of prioritizing officially-disseminated paratexts created for a media-derived anniversary, this article has instead addressed fans' affective reactions to such an occasion. Through doing this, a number of developments to emerging debates within both Television Studies and Fan Studies have been provided. Regarding the former, focusing on a case study of Twin Peaks's unusual silver jubilee has allowed for refining existing knowledge regarding the different anniversary 'types' that are constructed by media organizations and fan audiences are encouraged to negotiate. These types include both textual and paratextual returns, and praeventus and inseperatus in media res anniversaries, which relate to both the narrative level (e.g. diegetic or extra-diegetic) and official anticipation demonstrated towards the anniversary event. With regard to studies of fans and audiences for these occasions, addressing fan comments has allowed the unquestioned assumption that all forms of affect directed towards an anniversary return will be positive by demonstrating that fan interpretations instead range from enthusiasm through to ambivalence (tinged with 
negotiations of nostalgia) and outright rejection. What's more, through returning to Grossberg's theories of affect and applying these to an instance of paratextual return, it has been indicated that a range of contextual structures contribute towards producing different encodings of affective textualities. These expressions range from affective generalizations, where respondents convey their feelings about a paratextual return in short, succinct ways, through to affective-temporal focalizations where specific constructions of the fan text and/or its meanings to an individual fan's identity, both 'then' and 'now', are negotiated. Moving forward, then, greater attention should continue to be paid towards exploring the different types of media-derived anniversaries that are industrially-produced and targeted towards fan audiences with a view to better understanding how these different forms, and the platforms through which they are discussed, generate a range of affective responses. What other forms of affective textuality are articulated by fans? Are specific forms of affective focalization unique to specific fan communities and do these differ in accordance to the cultural form being discussed and the space where (para)textual returns are discussed? Through exploring these questions in greater detail, scholarly discussion can move away from the analysis of centrally-controlled and brand-managed (para)textual returns to instead embrace the affective textualities and discourses that fans articulate and so better understand how, why, where and whether these occasions matter.

\section{References}

Anstead, Nick and O’Loughlin, Ben (2011), 'The Emerging Viewertariat and BBC Question Time: Television Debate and Real-time Commenting Online', The International Journal of Press/Politics, 16: 4, pp. 440-462. 
Bell, Stuart and Deller, Ruth A (forthcoming), 'Endings in Soap Opera: Fan Anticipation, Speculation and Reaction to EastEnders' $30^{\text {th }}$ Anniversary Storyline', in R Williams (ed.) After the end: , Iowa City: University of Iowa Press, pp. XX-XX.

'Beyond Life and Death' (1991), David Lynch (dir.), Twin Peaks, Season 2 Episode 22 (18 June, USA: ABC/Lynch-Frost Productions).

Bourdieu, Pierre (1984), Distinction: A Social Critique of the Judgement of Taste, London: Routledge.

Boym, Svetlana (2001), The Future of Nostalgia, New York: Basic Books.

Couldry, Nick (2000), Inside Culture: Re-imagining the Method of Cultural Studies, London: Sage.

Daily Mail (n.d.), 'House rules', MailOnline, http://www.dailymail.co.uk/home/house_rules.html. Accessed 11 December 2016.

Davis, Fred (1979), Yearning for Yesterday: A Sociology of Nostalgia, London: Collier MacMillan.

Deamer, David (2015), 'Time Travel and Temporal Paradox: Deleuze, the Time-image and Russian Ark', in M Jones and J Ormrod (eds) Time Travel in Popular Media: Essays on Film, Television, Literature and Video Games, Jefferson: McFarland and Company, Inc., pp. 35-50.

Deleuze, Gilles (1986), Cinema I: The Movement-Image. Minneapolis: University of Minnesota Press.

Deller, Ruth (2014), 'The Art of Neighbours Gaming: Facebook, Fan-created Games and Humour', Intensities: The Journal of Cult Media, 7, pp. 97-106.

Doctor Who (1963-1989, 1996, 2005- , UK: BBC).

Duffett, Mark (2013), Understanding Fandom: An Introduction to the Study of Media Fan Culture, London: Bloomsbury. 
EastEnders (1985- , UK: BBC).

Fiske, John (1992), 'The Cultural Economy of Fandom', in L Lewis (ed.) The Adoring Audience: Fan Culture and Popular Media, London: Routledge, pp. 30-49.

Garner, Ross (2016), “'It is Happening Again”: Paratextuality, 'Quality’ and Nostalgia in Twin Peaks's Dispersed Anniversary', Series: International Journal of TV Serial Narratives, 11: 2, pp. 41-54.

— (forthcoming), 'Not my Lifeblood: Autoethnography, Affective Fluctuations and Antifandom', in P Booth (ed.) A Companion to Fandom and Fan Studies, London: WileyBlackwell, pp. 202-236.

Gergen, Kenneth J (1999), An Invitation to Social Construction, London: Sage.

Gray, Ann and Bell, Erin (2013), History on Television, London: Routledge.

Gray, Jonathan (2003), 'New Audiences, New Textualities: Anti-fans and Non-fans', International Journal of Cultural Studies, 6:1, pp. 64-81.

— (2010), Show Sold Separately: Promos, Spoilers and other Media Paratexts, New York: New York University Press.

Grossberg, Laurence (1992a), We Gotta Get Out of This Place: Popular Conservatism and Postmodern Culture, London: Routledge.

— (1992b), 'Is There a Fan in the House?: The Affective Sensibility of Fandom', in L Lewis (ed.) The Adoring Audience: Fan Culture and Popular Media, London: Routledge, pp. 50-65.

Halskov, Andreas (2015), TV Peaks: Twin Peaks and Modern Television Drama, Odense: University Press of Southern Denmark.

Hardy, Jonathan (2011), 'Mapping Commercial Intertextuality: HBO’s True Blood', Convergence: The International Journal of Research into New Media Technologies, 17: 1, pp. 7-17. 
Hayes, Marisa C and Boulègue, Franck (2013), (eds.) Fan Phenomena: Twin Peaks, Bristol: Intellect.

Hills, Matt (2002), Fan Cultures, London: Routledge.

— (2010a), 'Subcultural Celebrity', in S Abbott (ed.) The Cult TV Book, London: I.B. Tauris, pp. 233-238.

— (2010b), Triumph of a Time Lord: Regenerating Doctor Who in the Twentty-First Century, London: I.B. Tauris.

— (2013) 'Anniversary Adventures in Space and Time: The Changing Faces of Doctor Who's Commemoration', in M Hills (ed.), New Dimensions of Doctor Who: Adventures in Space, Time and Television, London: I.B. Tauris, pp. 216-234.

— (2014), 'When Doctor Who Enters its Own Timeline: The Database Aesthetics and Hyperdiegesis of Multi-Doctor stories', Critical Studies in Television, 9: 1, pp. 95113.

— (2015a), Doctor Who: The Unfolding Event-Marketing, Merchandising and Mediatizing a Brand Anniversary, Basingstoke: Palgrave Macmillan.

— (2015b) “"I'll See You Again in 25 Years”: Paratextually Re-commodifying and Revisiting Anniversary Twin Peaks', in J A Weinstock and C Spooner (eds.) Return to Twin Peaks: New Approaches to Materiality, Theory and Genre on Television, Basingstoke: Palgrave Macmillan, pp. 193-210.

Holdsworth, Amy (2011), Television, Memory and Nostalgia, Basingstoke: Palgrave Macmillan.

Howard, Doug (2015), 'Déjà Vu: Remakes, Reboots and the Future of Television', CSTOnline, November 27, http://cstonline.tv/deja-view-remakes-reboots. Accessed 27 November 2015. 
Johnson, Randall (1993) 'Editor's Introduction: Pierre Bourdieu on Art, Literature and Culture', in P Bourdieu (1993) The Field of Cultural Production: Essays on Art and Literature, Cambridge: Polity Press, pp. 1-25.

Jowett, Lorna, Robinson, Kevin and Simmons, David (2016), 'Timey Wimey Stuff:

Introduction to Time on TV', in L Jowett, K L Robinson and D Simmons (eds.) Time on TV: Narrative Time, Time Travel and Time Travellers in Popular Television Culture, London: I.B. Tauris, pp. 1-14.

Kuhn, Annette (2002), An Everyday Magic: Cinema and Cultural Memory, London: I.B. Tauris.

Lindloff, Thomas R and Taylor, Bryan C (2011), Qualitative Communication Research Methods, $3^{\text {rd }}$ Edition, London: Sage.

Lizardi, Ryan (2014), 'The Nostalgic Revolution will be Televised', in C Lavigne (ed.) Remake Television: Reboot, Re-use, Recycle, Plymouth: Lexington Books, pp. 37-52. Lynch, David (1992), Twin Peaks: Fire Walk with Me, USA: New Line Cinema.

— (2014), 'Between Two Worlds', Twin Peaks: The Entire Mystery, Blu-ray extras, Burbank, CA: CBS Home Entertainment.

Markham, Annette and Buchanan, Elizabeth (2012), 'Ethical Decision-making and Internet Research: Recommendations from the AoIR Ethics Working Committee (version 2.0)', Association of Internet Researchers, http://aoir.org/reports/ethics2.pdf. Accessed 11 December 2016.

Maxwell, Erin (2014), 'David Lynch returns to Twin Peaks as the director begins shooting new footage for the beloved cult series', MailOnline, January 7 , http://www.dailymail.co.uk/tvshowbiz/article-2535056/David-Lynch-returns-TwinPeaks-director-begins-shooting-new-footage-beloved-cult-series.html. Accessed 7 January 2014. 
Mittell, Jason (2015), Complex TV: The Poetics of Contemporary Television Storytelling, New York: New York University Press.

Murray, Simone (2005), 'Brand Loyalties: Rethinking Content within Global Corporate Media', Media, Culture and Society, 27: 3, pp. 415-435.

Proctor, William (2012), 'Regeneration and Rebirth: Anatomy of the Franchise Reboot', Scope: An Online Journal of Film and Television Studies, 22, February, pp. 1-19.

— (2013), “"Holy Crap! More Star Wars! More Star Wars? What If they're Crap?”: Disney, Lucasfilm and Star Wars Online Fandom in the $21^{\text {st }}$ Century', Participations: Journal of Audience and Reception Studies, 10: 1, pp. 198-224.

Quantcast (n.d.), 'welcometotwinpeaks.com - Quantcast', Quantcast, https://www.quantcast.com/welcometotwinpeaks.com. Accessed 8 August 2016.

Spigel, Lynn and Jenkins, Henry (1991), 'Same Bat Channel, Different Bat Times: Mass Culture and Popular Memory', in R E Pearson and W Uricchio (eds.) The Many Lives of the Batman: Critical Approaches to a Superhero and his Media, London: Routledge, pp. 117-148.

Tannock, Stuart (1995), 'Nostalgia Critique', Cultural Studies, 9: 3, pp. 453-464.

Thompson, Robert J (1997), Television's Second Golden Age: From Hill Street Blues to ER, New York: Syracuse University Press.

Thurman, Neil (2008), 'Forums for Citizen Journalists? Adoption of User Generated Content Initiatives by Online News Media', New Media and Society, 10: 1, pp. 139-157.

Tryon, Chuck (2013), 'Reboot Cinema’, Convergence: The International Journal of Research into New Media Technologies, 19: 4, pp. 432-437.

Turvill, William (2016), 'Website ABCs: Mail Online attracts new record 14.8m unique daily browsers and 238m over month', PressGazette, February 18, 
http://www.pressgazette.co.uk/website-abcs-mail-online-attracts-new-record-148munique-daily-users-and-238m-over-month/. Accessed 11 March 2017.

Twin Peaks (1990-1991, US: ABC/Lynch-Frost Productions).

Twin Pie (2014a), 'David Lynch to shoot Twin Peaks promo with busty brunette or redhead, confirmed by Ray Wise!', Welcome to Twin Peaks, http://welcometotwinpeaks.com/news/twin-peaks-promo-casting-call/. Accessed 3 January 2014.

— (2014b), 'Ray Wise hints at Twin Peaks "25 years later", Welcome to Twin Peaks, http://welcometotwinpeaks.com/news/twin-peaks-25-years-later-raywise/\#ixzz4HaqG75do. Accessed 13 January 2014.

— (2014c), 'Twin Peaks Blu-ray: What to expect?', Welcome to Twin Peaks, http://welcometotwinpeaks.com/news/twin-peaks-blu-ray/. Accessed 23 July 14.

Williams, Rebecca (2013), 'Tweeting the TARDIS: Interaction, Liveness and Social Media in Doctor Who Fandom', in M Hills (ed.), New Dimensions of Doctor Who: Adventures in Space, Time and Television, London: I.B. Tauris, pp. 154-173.

— (2015), Post-Object Fandom: Television, Identity and Self-Narrative, London: Bloomsbury. 